\title{
Redescription of the cestode Polyonchobothrium Clarias and its histopathological impact on the stomach of Clarias gariepinus
}

\author{
Abdalla M. Ibrahim ; Hoda A. Taha and Marwa M. El-Naggar \\ Faculty of Science, Ain-Shams University, Abbassia, Cairo, Egypt.
}

\begin{abstract}
This study was designed to redescribe the cestode Polyonchobothrium clarias 1 that has been recovered from the stomach of Clarias gariepinus, in addition to the ultrastructure of the parasite and the histopathological changes of the stomach of Clarias gariepinus infected with this parasite. Samples of $C$. gariepinus were dissected and examined for parasites and prepared for SEM, while the stomach of the host was prepared for histological observations. There were significant differences between normal fish and infected ones, where the stomach of normal fish exhibited continuous mucosal layer with well developed tubules and ducts with little infiltration of lymphocytes, while a remarkable damage was observed in the mucosal layer of the stomach of the infected fish with excessive infiltration of lymphocytes in addition to excessive mucous secretion and subsequent fibrosis. This study has provided further information on Polyonchobothrium clarias that can reveal more information about host-parasite relationships, particularly its impact on the host fish.
\end{abstract}

Keywords: redescription, ultrastucture, Polyonchobothrium clarias, Clarias gariepinus, histopathology, host-parasite relationship.

\section{INTRODUCTION}

Clarias gariepinus (Burchell, 1822), family Clariidae is generally considered to be one of the most important tropical catfish species for aquaculture in West and North Africa (Clay, 1979). A number of gastrointestinal helminth worms have been reported in C. gariepinus by Yakubu et al. (2002) in Plateau state located in West Africa and Oniye et al. (2004) in Zaria, Nigeria. The latter authors reported the occurrence of cestodes, Anomotaenia sp. (2.5\%), Monobothrium sp. (13.33\%) and Polyonchobothrium clarias (1.67\%); the Nematode, Procamallanus laevionchus and the acanthocephalan, Neoechinorhynchus rutli (0.83\%) in the present fish(Hoffman,1971).

Tapeworms have a worldwide distribution and are parasites of many species of fish. Adult worms can be easily found in fish's intestines and pyloric caeca.

Cestodes infecting Clarias gariepinus include: Polyonchobothrium clarias, Stocksia pujehuni, Wenyoni acuminata, Anomotaenia sp., Monobothrium sp. and Proteocephalus sp .(Paperna,1996). 
The present study aimed to redescribe Polyonchobothrium clarias based on its ultra structure in addition to the histopathological changes of the stomach of Clarias gariepinus naturally infected with this parasite.

\section{MATERIALS AND METHODS}

Samples of Clarias gariepinus were brought from different local markets in Cairo, Egypt. The gastrointestinal tract was dissected out of the fish from the oesophagus to the rectum and parasites encountered were carefully detached from the stomach or the intestinal mucosa.

The parasite samples were recovered from naturally infected C. gariepinus and fixed in $10 \%$ formalin, then washed in distilled water and stained in Borax Carmine for 24 hours.

\section{PREPARATION OF PARASITES FOR SCANNING ELECTRON MICROSCOPY (SEM):}

Worms were washed thoroughly using distilled water, fixed in $10 \%$ formalin and post fixed for about 2 hours, using $2.5 \%$ glutraldehyde series of acetone (El Naggar et al., 1993). Critical point drying was carried out using a polaron critical point drying unit with carbon dioxide as a transition fluid. Subsequently, the dried specimens were sputter coated with a thin layer of gold using JEOL model JFC1100F sputtering device. SEM observations were conducted using JEOL, model JTM-1200 EXLL - Japan, at the Electron microscope unit in the central laboratory of Faculty of Science at Ain Shams University.

\section{HISTOLOGICAL PREPARATION OF THE FISH STOMACH:}

Standard microtechnique procedures were used to prepare transverse sections of the stomach which were embedded in wax, then in the incubator with a curing point of 60 Celsius in the laboratory. The specimens were sectioned at $6 \mu \mathrm{m}$ thickness and then left in incubator for three days and then processed for staining with $\mathrm{HX}$ and $\mathrm{E}$.

\section{RESULTS}

Based on light microscopic examination and comparing with the published descriptions of the parasite, it was clear that it belongs to Polyonchobothrium clarias (Woodland, 1925).

DESCRIPTION:

Scolex rectangular with a flat to slightly raised apex (rostellum) (Figs.1 and 2) armed with a crown of 26-30 hooks (mean 28; $\mathrm{n}=6$ ). Apex is divided into two semicircles, each bearing 13-15 hooks. Hooks at the end of each semicircle are smaller than the others, as shown by SEM (Fig.4).

Two longitudinally elongated bothria are lined with the gaps between the crowns of hooks (Fig.4). Immature proglottids of strobila not completely segmented (Fig.1). Some mature segments appeared fused as shown by SEM 
(Fig.5). Testes medullary; uterus anterior to ovary, highly folded and occupying the greater portion of gravid proglottids.

\section{HISTOPATHOLOGICAL OBSREVATIONS:}

A comparison was done between the non infected stomash of Clarias gariepinus and an infected one. Such comparison revealed the following differences: The normal fish stomach has a normal continuous mucosal layer, where the columnar cells were firmly attached to each other and the mucosa showed a little infiltration of lymphocytes(Fig.7).

Pathological changes appear in infected fish, which include pressure lesions, inflammation of the intestine and severe "catarrhal-haemorrhagic enteritis" at the parasite attachment point, with proliferation of the peripheral connective tissue. In addition to these effects, the infected fish stomach revealed a remarkable damage of the mucosal layer and loss of cohesion of the columnar epithelium (Fig.12). A high amount of mucous appeared covering the whole stomach especially at the sites where the scoleces of the parasite were embedded (Fig.8 ). Excessive infiltration of lymphocytes and fibrosis of the mucosal layer were markedly shown, indicating the adverse impact of infection (Fig.11).

\section{DISCUSSION}

Polyonchobothrium clarias is a widely distributed cestode in African freshwater siluroid fishes, having been recorded from Nigeria in the North African catfish Clarias lazera (= C. gariepinus) Cuvier \& Valenciennes, 1840 (Aderounmu \& Adeniyi, 1972. It was also reported in the Bagrid catfish Chrysichthys thonneri Steindachner, 1912 from Gabon, the mud-fish Clarias anguillaris (Linnaeus, 1758)and (Amin, 1978) from Egypt and Heterobranchus bidorsalis Geoffroy Saint-Hilaire, 1809 from Senegal (Khalil, 1973). In southern Africa, P. clarias was first observed and recorded by Mashego (1977) from C. gariepinus in seven dams in the Le bowa region, Limpopo Province, South Africa. The only other record of the parasite was from the Middle Letaba Dam also in the above province (Saayman et al., 1991). Its high prevalence in the Rietvlei system, as well as in the Vaal Dam ( Barson \& Avenant-Oldewage, unpublished data 2003), seems to suggest that the cestode is widely distributed in C. gariepinus in the country . In Zimbabwe, Chishawa (1992) and Douëllou (1992) recorded an intestinal cestode from the brown squeaker, Synodontis zambezenis Peters, 1852, and C. gariepinus from Lake Kariba. Although they mistook it for larval $P$. clarias, it was apparently an adult with $r \wedge$ hooks on its apical crown. Larvae only occur in copepod intermediate hosts. Barson \& Avenant-Olde wage (unpublished data, 2003) recorded more than 100 individuals infecting one specimen of C. gariepinus in the Vaal Dam. The fact that the tapeworms physically resisted detachment from the gut mucosa suggests that the suction created by the bothria and the clasp of the apical hooks could cause severe pathological effects in heavy infections. 
The present specimens seems to differ from those described by Saayman et al. (1991) only in that their material had a "triangular scolex and they found some specimens in the main bile duct of the host, which they described as "more robust" than the intestinal specimens. They did not find the parasite in the stomach as in the present case and neither did they give the number and size of the hooks on the scolex. According to the generic diagnosis of Polyonchobothrium given by Yamaguti (1959), the apex of the scolex (rostellum) is distinctly elevated, a characteristic observed by Saayman et al. (1991), which was not evident in any of the specimens from Rietvlei. Scanning Electron Micrographs (SEM) of the present specimens also show a more or less flattened rostellum .

Specimens of $P$. clarias from Nigeria, however, had a "bulbous scolex with a circle of 32 hooks arranged in four quadrants of eight hooks each" (Aderounmu \& Adeniyi, 1972), which is more closely resembles $P$. polypteri (Jones 1980). Yamaguti's genus Polyonchobothrium (1959) is characterized by a nearly rectangular scolex with hooks arranged in four quadrants. It seems therefore that $P$. ophiocephalina from Chinese perch (Zhongzhang, 1982) and P. magnum from Russia (Bykhovskaya-Pavlovskaya et al., 1962), are exceptions to this rule, having a "conical scolex" similar to that observed by Mashego (1977) and Saayman et al. (1991) and a trapezoidal scolex respectively.

The number of apical hooks in P. clarias from the Rietvlei Dam (26-30) differs significantly from those infecting fish in Egypt (37-41; Amin ,1978), Nigeria (32;Aderounmu \& Adeniyi, 1972) and Zimbabwe (38; Chishawa, 1991). Unfortunately, previous studies on this parasite in South Africa did not indicate the number of hooks on the apical crown. The SEM study on the present specimens confirmed the central placing of the uterine pore on the ventral surface of each proglottid.

Hoffman (1980) reported that the intestines of infected small fish, such as the golden shiner, become plugged by the worms and in some instances are perforated. Minnow farmers report mortality among infected stocks. Laboratory experiments also demonstrated that mortality caused by tape worms was a function of parasite density and host size. At elevated temperature $\left(25\right.$ to $30^{\circ} \mathrm{C}$ ), survival of both infected and non infected fish declined, but infected fish died sooner.

Accurate evaluation of the pathological effects of infection should be related not only to worm burden, but also to the size and condition of the host. Although the Asian tape worm is not fastidious in the choice of host, it may have different degrees of compatibility with different host species, which may also be expressed as variation in tolerance and defense response among infected fish species. 
From the present study, it could be concluded that even one cestode worm such as Polyonchobothrium clarias could adversily affect the host fish and thus have a negative impact on its vitality and persistence.

\section{REFRENCES}

Aderounmu, E. A. and Adeniyi, F. (1972). Cestodes in fish from a pond at Ile-Ife, Nigeria. The African Journal of Tropical Hydrobiology and Fisheries, 2: 151-156.

Amin, O.M. (1978). Intestinal helminths of some Nile fishes near Cairo, Egypt, with redescriptions of Camallanus kirandensis Baylis, 1928 (Nematoda) and Bothriocephalus aegyptiacus Rysavy and Moravec, 1975 (Cestoda). Journal of Parasitology 64: 93-101.

Bykhovskaya-Pavlovskaya, I.E.; Gusev, A.V.; Dubinia, M.N.; Izgumova, N.A.; Smirnova, T.S.; Sokolovskaya, I.L.; Shtein, G.A.; Shulman, S.S. \& EPSHTEIN, V.M. (1962). Key to parasites of freshwater fish in the USSR. Israel Program for Scientific Translations, Jerusalem. Translated from Russian in 1964.

Chishawa, A.M.M. (1991). A survey of the parasites of three Siluriformes fish species in Lake Kariba. University Lake Kariba Research Station Bulletin, $1 / 91$.

Douëllou, L. (1992). A survey of fish parasites in Lake Kariba. University Lake Kariba Research Station Bulletin, 1/92. Kariba: University of Zimbabwe.

El Naggar, M. M.; Ibrahim, H. A. and Hamada, S.F (1993). Scanning and transmission electron microscope observations on the general body tegument and Ventral pads of the digenean Orientocreadium batrachoides Tubangui , (1931). J. Egypt Ger. Soc. Zool., 10 (D):245-264.

Hoffman, G. L. and Bauer, O. N. (1971). Fish parasitology in water reservoirs: A review. In: G.E. Hall, (Ed) Reservoir fisheries and limnology. American Fisheries Society, Washington, D.C.

Hoffman, G. L. (1980). Asian tapeworm, Bothriocephalus acheilognathi Yamaguti, 1934, in North America. Fisch und Umvelt, Special volume in honor of Prof. Dr H.-H. Reichenbach -Klinke 65th Birthday.8: 69 - 75.

Jones, A. (1980). Proteocephalus pentastoma (Klaptocz, 1906) and Polyonchobothrium polypteri (Leydig, 1853) from species of Polypterus 
Lebelo, S.L.; Saunders D.K. and Crawford, T.G. (2001). Observations on the blood viscosity in stripped bass, Walbaum associated with fish hatchery conditions .transaction of the kanasas Academy of Science, 104 (314): 183-194.

Mashego, S.N. (1977). A seasonal investigation of the ecto- and endoparasites of the Barbel, Clarias gariepinus (Burchell, 1822) in Lebowa, South Africa. Unpublished M.Sc. thesis, University of the North, South Africa.

Paperna, I. (1996). Parasites, infections and diseases of fishes in Africa: An update. FAO/CIFA Technical Paper, No. 31.

Saayman, J.E.; Mashego, S.N. and Mokgalong, N.M. (1991). Parasites of the fish population with notes on the helminth parasites of the water birds of Middle Letaba Dam. In: J.E. Saayman, H.J. Schoonbee \& G.L. Smit, (eds.) A post impoundment ecological study of the Middle Letaba Dam, Gazankulu. Department of Development Aid, Pretoria.

Yamaguti, S. (1959). Systema Helminthum. Vol. II. The cestodes of vertebrates. Interscience Publishers, Inc., New York \& London.

Zhongzhang, T. (1982). Developmental studies on Polyonchobothrium ophiocephalina (Tseng, 1933) and Bothriocephalus opsariichthydis Yamaguti, (1934): Acta Zoologica Sinica, 28: 51-59. In Chinese. 


\section{EXPLANATION OF FIGURES}

Fig.(1): Photomicrograph showing the scolex, immature proglottids and the beginning of the mature proglottids of $P$. clarias $(10 \mathrm{x})$.

Fig. (2): photomicrograph of the scolex of P.clarias (40x).

Fig. (3): Scanning Electro micrograph of enlarged portion of the scolex of $P$. clarias, showing the 13-15 hooks at each semicircle and hooks at each end of the semicircle are smaller than others (3000x).

Fig.(4): Scanning Electro micrograph showing the scolex of $P$. clarias with the crown of hooks and the longitudinal bothria. (800x).

Fig (5): Scanning Electro micrograph showing the gential pore in the mature proglottids of $P$. clarias that are apparently fused. (3000x).

Fig.(6): Photomicrograph of mature proglottis of $P$. clarias showing, the genital pores and gonads $(40 \mathrm{x})$.

Fig.(7): Photomicrograph of T.S of stomach of non infected Clarias gariepinus, showing an area of mucosal layer with little infiltrating lymphocytes.

Fig.(8): Scanning Electro micrograph of the stomach of infected Clarias gariepinus, showing Polyonchobothrium clarias scoleces embedded into the mucosa of the stomach. (325x).

Fig.(9): Photomicrograph showing parts of Polyonchobothrium clarias embedded in the mucosa of the stomach of Clarias gariepinus. (10x).

Fig.(10): Photomicrograph showing a transverse section of the scolex of $P$. clarias embedded in the mucosa of stomach of Clarias gariepinus $(40 \mathrm{x})$.

Fig.(11): Photomicrograph of T.S of stomach of Clarias gariepinus showing the excessive infiltration of lymphocytes due to its infection with P. clarias. $(40 \mathrm{x})$.

Fig.(12): Photomicrograph showing the excessive damage of the mucosal layer of the stomach of Clarias gariepinus infected with P. clarias. (40x). 


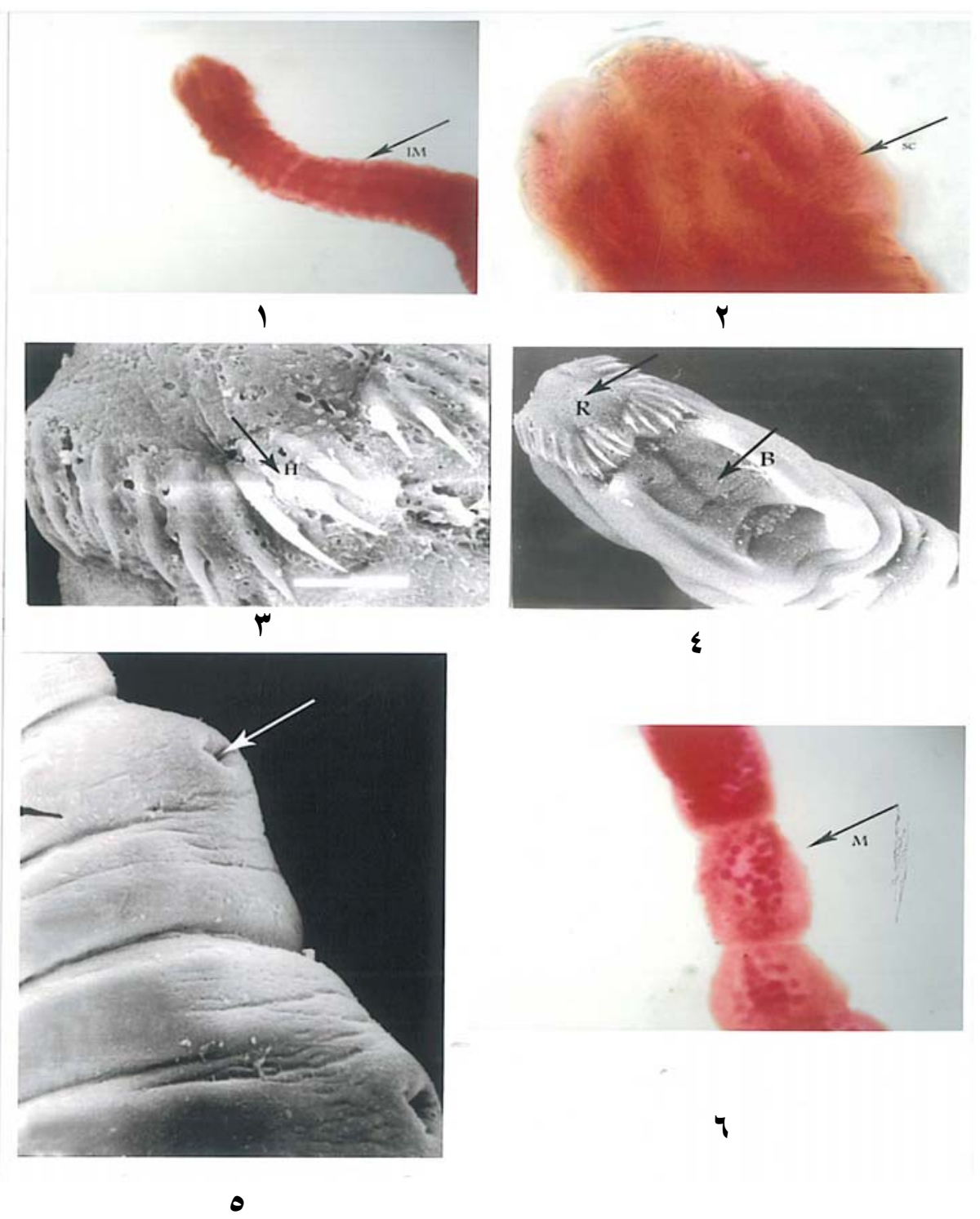




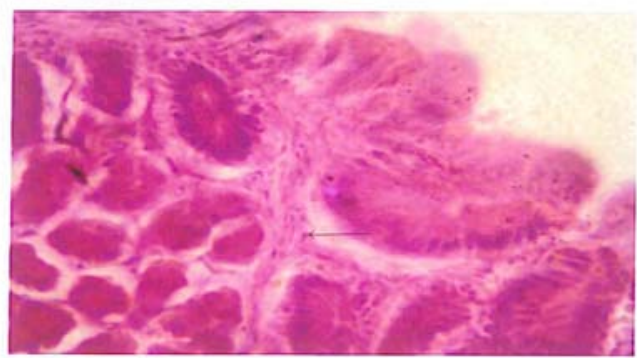

V

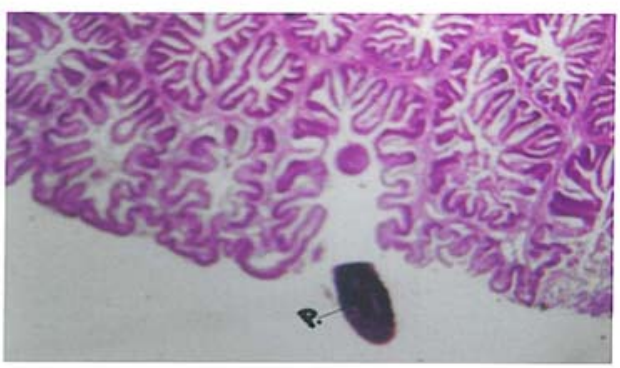

9

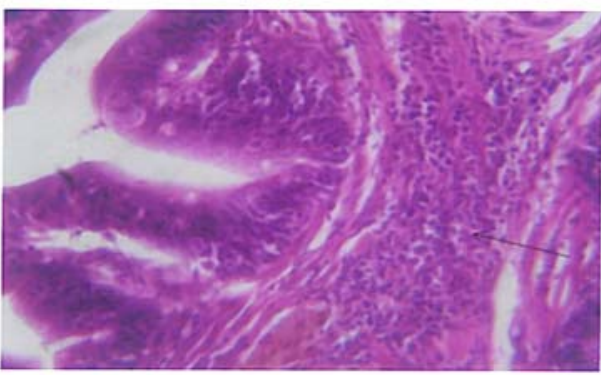

11

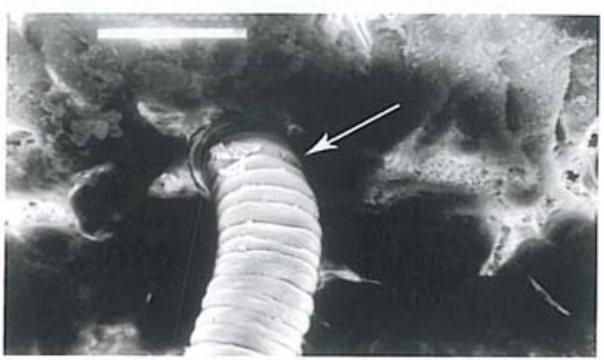

$\wedge$

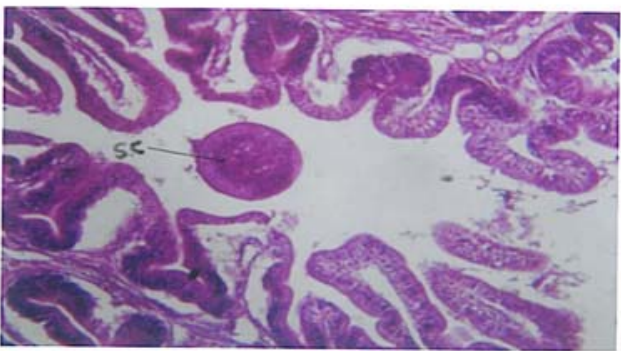

1.

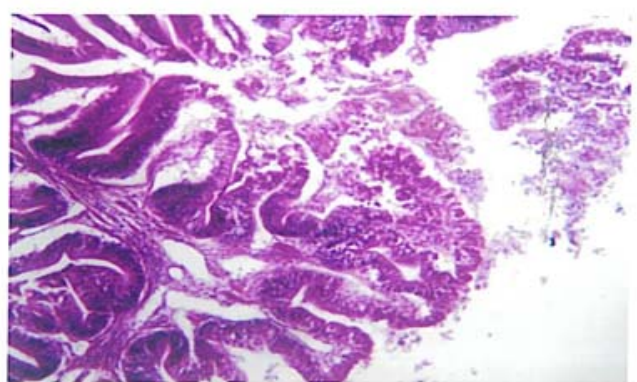

Ir 